\title{
One-Year Outcome of Geriatric Hip-Fracture Patients following Prolonged ICU Treatment
}

\author{
Daphne Eschbach, Christopher Bliemel, Ludwig Oberkircher, Rene Aigner, Juliana Hack, \\ Benjamin Bockmann, Steffen Ruchholtz, and Benjamin Buecking
}

Center for Orthopaedics and Trauma Surgery, University Hospital Giessen and Marburg GmbH, Location Marburg, Baldingerstraße, 35043 Marburg, Germany

Correspondence should be addressed to Daphne Eschbach; eschbach@med.uni-marburg.de

Received 12 October 2015; Revised 5 December 2015; Accepted 13 December 2015

Academic Editor: Hitendra K. Doshi

Copyright ( 2016 Daphne Eschbach et al. This is an open access article distributed under the Creative Commons Attribution License, which permits unrestricted use, distribution, and reproduction in any medium, provided the original work is properly cited.

\begin{abstract}
Purpose. Incidence of geriatric fractures is increasing. Knowledge of outcome data for hip-fracture patients undergoing intensivecare unit (ICU) treatment, including invasive ventilatory management (IVM) and hemodiafiltration (CVVHDF), is sparse. Methods. Single-center prospective observational study including 402 geriatric hip-fracture patients. Age, gender, the American Society of Anesthesiologists (ASA) classification, and the Barthel index (BI) were documented. Underlying reasons for prolonged ICU stay were registered, as well as assessed procedures like IVM and CVVHDF. Outcome parameters were in-hospital, 6-month, and 1year mortality and need for nursing care. Results. $15 \%$ were treated $>3$ days and $68 \%<3$ days in ICU. Both cohorts had similar ASA, BI, and age. In-hospital, 6-month, and 12-month mortality of ICU $>3 \mathrm{~d}$ cohort were significantly increased $(p=0.001)$. Most frequent indications were cardiocirculatory pathology followed by respiratory failure, renal impairment, and infection. $18 \%$ of patients needed CVVHDF and 41\% IVM. In these cohorts, 6 -month mortality ranged $>80 \%$ and 12 -month mortality $>90 \%$. $100 \%$ needed nursing care after 6 and 12 months. Conclusions. ICU treatment $>3$ days showed considerable difference in mortality and nursing care needed after 6 and 12 months. Particularly, patients requiring CVVHDF or IVM had disastrous long-term results. Our study may add one further element in complex decision making serving this vulnerable patient cohort.
\end{abstract}

\section{Introduction}

By $2030,25 \%$ of the western European population is expected to be at least 65 years of age [1]; by 2050, the elderly population will almost triple [2].

Until the age of $85,11 \%$ of women and $5 \%$ of men are hospitalized because of femoral fractures [3, 4]. Longterm mortality in this cohort, compared with people of the same age without fracture, is $1.15: 1$, a $20 \%$ increase [5]. Thus, successful treatment of these fractures is becoming increasingly important. Over the last years, several models of shared orthogeriatric care have been developed worldwide to improve patients' outcomes. As part of these models, a perioperative observational period was developed as a standard procedure for this patient sample. Monitoring in the postoperative period is also part of current guidelines [6, 7]. Triage studies have demonstrated that patients admitted to
ICUs have improved survival compared to rejected patients [8-10]. Elderly patients may have worse prognoses because of more comorbid conditions and fewer physiologic reserves. Some authors recently documented age as an independent risk factor for mortality $[11,12]$ but not always a factor in predicting worse outcome [13]. Today, plenty of data concerning comorbidities and chronic health conditions identified as risk factors, especially for hip-fracture patients' outcomes, are available. They are associated with poor outcomes (i.e., prolonged hospitalization, higher complication rate, poorer functional levels, and increased mortality) $[14,15]$. With the current aging population, more complex procedures, and increasing expectations, demand for ICUs will increase further. Particularly, pulmonary complications and renal failure due to a preexisting chronic failure are severe and life-limiting complications. It is reported that incidence of hospitalization secondary to community-acquired pneumonia doubles in 
patients aged $>60$ years [16]. Posthospitalization outcome data following ICU-dependent complications in geriatric trauma patients are sparsely available. In particular, outcome data after invasive ventilation and filtration due to acute renal failure do not exist for this kind of cohort. Furthermore, short-term survival is probably not the most important factor considered when making treatment decisions in this cohort; we suggest that invasive ICU procedures may increase the likelihood of less favorable post-ICU outcomes such as persistent need of nursing care.

Accordingly, dependent on reasons and assessed procedures for an ICU treatment extending past the normal postoperative period of 1 to 3 days, we aimed to detect considerable differences in 6- and 12-month mortality as well as persistent need of nursing care of these patients.

\section{Patients and Methods}

Patients at least 60 years old with proximal femoral fractures (ICD 10 S 72.0-72.2) were included in this prospective singlecenter observational study. Research nurses and/or senior physicians collected data.

Criteria for exclusion were multiple traumas (ISS $\geq 16$ ) and malignoma-associated fractures. All patients were surgically treated with either internal fixation or hip arthroplasty. The inclusion period was from April 1, 2009, to September 30, 2011. We obtained the approval of the Ethics Committee of the University of Marburg (AZ 175/08). All of the patients or their legal representatives gave their written consent.

We documented patient age, gender, the American Society of Anesthesiologists (ASA) classification, and fracture type. Patients were requested to give information about their prefracture functional status. We measured the functional status by the Barthel index (BI, Hamburg Classification Manual). We registered the prevalence of ICU stay, underlying reasons for admission, and length of stay in the ICU during the hospitalization period and assessed procedures like invasive ventilator management (IVM) and renal failure demanding CVVHDF. According to further evaluation, we subdivided our patients into 3 groups: those who were not treated in the ICU (nICU, i.e., no intensive-care unit), those who stayed 1 to 3 days in the ICU (sICU, i.e., short intensivecare unit), and those who stayed $>3$ days (pICU, i.e., prolonged intensive-care unit). We defined outcome parameters as in-hospital mortality, 6-month mortality and nursing dependency, and 1-year mortality and nursing dependency.

We collected data in a FileMaker database (FileMaker, Inc. 5201 Patrick Henry Drive Santa Clara, CA 95054, USA). We performed double entry with a plausibility check to improve data quality. We used Predictive Analysis Software (PASW) version 22.0 (SPSS Inc., Chicago, IL, USA) for descriptive statistics and explorative data analysis, with the results being presented as numbers and percentages or as means, standard deviations, and 95\% confidence intervals. We tested numerous data using the Wilcoxon test or the $t$ test, depending on the Kolmogorov-Smirnov test for normal distribution. We tested all dichotomies using Fisher's exact test. The outcome parameters in hospital mortality, 6-month mortality, and 12-month mortality were analyzed additionally by multivariate analysis addressing the covariates age, gender, BI, ASA, Charlson index, BMI, time until operation, and ICU cohort. For all tests, we assumed statistical significance at $p \leq 0.05$.

\section{Results}

In the observational period, we were able to include 402 patients. The baseline characteristics of all patients are illustrated in Table 1. Patients underwent operative treatment for hip-related fracture (intramedullary nail/hemiarthroplasty) in the first $24 \mathrm{~h}$. The pICU cohort was operated with a slight delay compared to the sICU cohort $(17.2 \pm 0.8 \mathrm{~h}$ versus $23.3 \pm$ $2.3 \mathrm{~h}, p=0.041$ ).

We observed $336(85 \%)$ of all patients in the ICU postoperatively for a mean of $2.5( \pm 3.7)$ days. The pICU group included 61 patients. None of the patients who were admitted directly to the standard-care unit required ICU admission in the course of inpatient care.

Patients with ICU stays were significantly older than those in group nICU ( $79 \pm 8$ versus $82 \pm 9, p=0.008)$. The ICU cohorts showed significantly more female patients and significantly higher ASA scores $(p \leq 0.001)$. Comparing the pICU cohort to the sICU cohort, the differences concerning the abovementioned characteristics seem to be sparse. Both groups had similar ASA, BI, and age. Nevertheless, the pICU cohort showed a significantly higher amount of prefracture nursing care needed, including 144 (52\%) in need of care versus $44(72 \%)$ patients in the sICU cohort $(p=0.042)$. CCI was also increased significantly in the pICU cohort $(p \leq$ 0.001).

Comparing the data of further clinical courses, the inhospital mortality of the pICU cohort was significantly increased (3\% versus 26\%). The 6- and 12-month mortality were equally increased and statistically significantly compared to the cohort of nICU patients and sICU patients as well (18\% versus $48 \%$ and $26 \%$ versus $59 \%$ ). The 6 -month and 12 -month nursing-care need showed equal tendency (67\% versus $85 \%$ and $66 \%$ versus $84 \%$ ) without reaching a statistically significantly higher amount in the pICU cohort ( $p=0.072$ versus $p=0.123$; Table 2$)$.

A multivariate analysis for the mortality endpoints "inhospital mortality," "6-month mortality," and "12-month mortality," including the variables age, gender, BI, ASA, Charlson index, BMI, time until operation, and ICU cohort, was performed. As expected, the ASA and ICU cohorts were independent risk factors affecting the different mortality endpoints. The Charlson index became significant in the 6and 12-month mortality analysis (Table 3).

As mentioned above, 61 patients were treated for more than 3 days in our ICU. Regarding the underlying reasons concerning a prolonged ICU treatment period, we noticed the main treatment diagnosis during stay: the largest group of 17 patients suffered from cardiac pathology subdivided into arrhythmia, ischemia, or failure. Two patients in this subgroup underwent cardiopulmonary resuscitation (CPR), 1 following ventricular fibrillation and 1 further following myocardial failure with cardiac arrest. The second largest group included primary respiratory failure $(N=10)$, renal 
TABLe 1: Baseline data, given as mean and standard deviation $( \pm)$ or as odds ratio with confidence interval (CI). For all tests, statistical significance was assumed at $p \leq 0.05$.

\begin{tabular}{|c|c|c|c|c|c|}
\hline & Given & $\mathrm{nICU}$ & sICU & $\mathrm{pICU}$ & $p=\mathrm{sICU} / \mathrm{pICU}$ \\
\hline Number of patients & $N=402$ & 66 & 275 & 61 & - \\
\hline \multirow{2}{*}{ Patients' age } & Mean (SD) & $79( \pm 8)$ & $82( \pm 8)$ & $82( \pm 9)$ & 0.970 \\
\hline & $95 \%$ CI & $77-81$ & $81-83$ & $80-84$ & - \\
\hline \multirow{2}{*}{ Gender } & Male (\%) & $14(21 \%)$ & $71(26 \%)$ & $24(39 \%)$ & - \\
\hline & Female (\%) & $52(79 \%)$ & $204(74 \%)$ & $37(61 \%)$ & 0.049 \\
\hline BMI & Mean (SD) & $16( \pm 33)$ & $18( \pm 29)$ & $19( \pm 28)$ & 0.999 \\
\hline ASA score & Mean (SD) & $2.7( \pm 0.7)$ & $2.9( \pm 0.6)$ & $3.1( \pm 0.6)$ & 0.107 \\
\hline \multirow{2}{*}{ Prefracture Barthel index } & $95 \% \mathrm{CI}$ & $2.5-2.8$ & $2.9-3.0$ & $2.9-3.2$ & - \\
\hline & Mean (SD) & $89( \pm 21)$ & $79( \pm 24)$ & $72( \pm 28)$ & 0.300 \\
\hline \multirow{2}{*}{ Prefracture nursing-care need } & $95 \% \mathrm{CI}$ & $83-94$ & $76-82$ & $65-80$ & - \\
\hline & $\%$ & $21(32 \%)$ & $144(52 \%)$ & $44(72 \%)$ & 0.042 \\
\hline \multirow{2}{*}{ Charlson score } & Mean (SD) & $1.7(2.2)$ & $2.3(2.1)$ & $3.6(2.8)$ & $<0.001$ \\
\hline & $95 \%$ CI & $1.1-2.2$ & $2.0-2.5$ & $2.9-4.3$ & - \\
\hline \multirow{2}{*}{ Time to operation/h } & Mean (SD) & $18.1(1.4)$ & $17.2(0.8)$ & $23.3(2.3)$ & 0.041 \\
\hline & 95\% CI & $15.2-21$ & $15.7-18.7$ & $18.7-27.9$ & - \\
\hline
\end{tabular}

TABLE 2: Mortality and nursing care dependence of ICU length of stay. *: survivors. For all tests statistical significance was assumed at $p \leq 0.05$

\begin{tabular}{lcccc}
\hline & nICU & sICU & pICU & $p=$ sICU/pICU \\
\hline In-hospital mortality $^{2}$ & $0(0)$ & $9(3 \%)$ & $16(26 \%)$ & $<0.001$ \\
6-month mortality & $4(6.1 \%)$ & $48(18 \%)$ & $29(48 \%)$ & $<0.001$ \\
12-month mortality* & $9(15.5 \%)$ & $60(26 \%)$ & $33(59 \%)$ & $<0.001$ \\
6-month nursing-care need & $22(42 \%)$ & $123(67 \%)$ & $23(85 \%)$ & 0.073 \\
12-month nursing-care need & $16(43 \%)$ & $101(66 \%)$ & $16(84 \%)$ & 0.123 \\
\hline
\end{tabular}

TABLE 3: Multivariate analysis of independent risk factors for in-hospital mortality (IHM), 6-month mortality (6 MM), and 12-month mortality (12 MM). OR: odds ratio; CI: confidence interval; BMI: body mass index.

\begin{tabular}{|c|c|c|c|c|c|c|c|c|c|}
\hline $\begin{array}{l}\text { Variables } \\
\text { Point of analysis }\end{array}$ & $\begin{array}{c}\text { OR } \\
\text { IHM }\end{array}$ & $\begin{array}{c}\mathrm{OR} \\
6 \mathrm{MM} \\
\end{array}$ & $\begin{array}{c}\text { OR } \\
12 \mathrm{MM} \\
\end{array}$ & $\begin{array}{c}95 \% \text { CI } \\
\text { IHM }\end{array}$ & $\begin{array}{c}95 \% \mathrm{CI} \\
6 \mathrm{MM}\end{array}$ & $\begin{array}{l}95 \% \mathrm{CI} \\
12 \mathrm{MM} \\
\end{array}$ & $\begin{array}{l}p \text { value } \\
\text { IHM }\end{array}$ & $\begin{array}{c}p \text { value } \\
6 \mathrm{MM}\end{array}$ & $\begin{array}{l}p \text { value } \\
12 \mathrm{MM}\end{array}$ \\
\hline Age & 0.980 & 1.031 & 1.032 & $0.919-1.004$ & $0.990-1.073$ & $0.994-1.072$ & 0.529 & 0.145 & 0.096 \\
\hline Gender & 1.080 & 0.582 & 0.653 & $0.330-3.534$ & $0.304-1.115$ & $0.394-1.223$ & 0.899 & 0.103 & 0.184 \\
\hline Barthel index & 1.000 & 0.997 & 0.992 & $0.979-1.021$ & $0.984-1.009$ & $0.980-1.004$ & 0.983 & 0.594 & 0.173 \\
\hline ASA & 3.085 & 2.147 & 2.160 & $1.059-8.985$ & $1.190-3.873$ & $1.241-3.758$ & 0.039 & 0.011 & 0.006 \\
\hline Charlson index & 1.048 & 1.160 & 1.196 & $0.847-1.296$ & $1.013-1.328$ & $1.050-1.362$ & 0.666 & 0.032 & 0.007 \\
\hline BMI & 0.993 & 1.001 & 1.003 & $0.978-1.007$ & $0.991-1.012$ & $0.993-1.013$ & 0.327 & 0.830 & 0.557 \\
\hline $\begin{array}{l}\text { Time until } \\
\text { operation }\end{array}$ & 1.001 & 1.002 & 1.000 & $0.969-1.003$ & $0.982-1.023$ & $0.980-1.020$ & 0.976 & 0.826 & 0.988 \\
\hline ICU cohort & 20.493 & 3.221 & 2.112 & $5.835-71.981$ & $1.792-5.793$ & $1.235-3.614$ & 0.000 & 0.000 & 0.006 \\
\hline Constant & 0.000 & 0.001 & 0.003 & - & - & - & 0.019 & 0.002 & 0.005 \\
\hline
\end{tabular}

impairment $(N=8)$, and infection $(N=9)$ as further numerous events demanding prolonged ICU treatment. Analytic separation of the underlying reasons is given in Table 4.

Following the further clinical course of these 61 patients, $11(18 \%)$ of them received at least transient CVVHDF and 25 (41\%) received IVM. In-hospital mortality showed to be
$82 \%$ in the CVVHDF group and $68 \%$ in the IVM group. The 6-month mortality ( $82 \%$ versus $88 \%$ ) and 12 -month mortality (91\% versus $92 \%$ ) ranged in both groups at equal levels without displaying statistical significance. Amounts of $100 \%$ are displayed concerning the 6-month and 12 -month nursing-care need (Table 5). 
TABLE 4: Reasons for admission to ICU in pICU cohort.

\begin{tabular}{lc}
\hline Reasons for ICU treatment $>$ 3 days & Number of patients \\
\hline Cardiac arrhythmia & 5 \\
Cardiac ischemia & 8 \\
Cardiac failure & 4 \\
Renal failure & 8 \\
Cholezystitis/cholangitis & 3 \\
Respiratory failure & 10 \\
Infection & 9 \\
Bowel pathology with need for surgical & 6 \\
intervention & 1 \\
$\begin{array}{l}\text { Epilepsy } \\
\text { Operative revision of surgical } \\
\text { complication }\end{array}$ & 2 \\
$\begin{array}{l}\text { Hepatic failure } \\
\text { Postoperative anemia/impaired } \\
\text { coagulation }\end{array}$ & 1 \\
\hline
\end{tabular}

TABLE 5: Mortality and nursing-care need after different assessments in pICU cohort. $*$ : survivors.

\begin{tabular}{lcc}
\hline & $\begin{array}{c}\text { Need for renal } \\
\text { filtration }\end{array}$ & $\begin{array}{c}\text { Need for invasive } \\
\text { ventilatory } \\
\text { management }\end{array}$ \\
\hline Number of patients & $N=11$ & $N=25$ \\
In-hospital mortality & $9(82 \%)$ & $17(68 \%)$ \\
6-month mortality* & $9(82 \%)$ & $22(88 \%)$ \\
12-month mortality* $^{*}$ & $10(91 \%)$ & $22(92 \%)$ \\
6-month nursing-care need & $2(100 \%)$ & $3(100 \%)$ \\
12-month nursing-care need & $1(100 \%)$ & $2(100 \%)$ \\
\hline
\end{tabular}

\section{Discussion}

With this prospective observational trial, we aimed to investigate long-term outcomes of geriatric hip-fracture patients who had had prolonged treatment in an ICU, particularly with regard to those undergoing invasive ventilation and renal filtration.

There are plenty of studies published that have focused on the meticulous demands of geriatric trauma patients in the last few years. Differentiated outcome data concerning geriatric hip-fracture patients, especially following invasive ventilation and hemodiafiltration due to acute lung failure or renal failure, did not exist for this special kind of cohort.

We know that, following hospital discharge, elderly patients are 2.3 times more likely to die in the long term compared to a similar age group in the general population [17]. A recent study dealing with the long-term outcome of elderly, critically ill patients showed 1-year mortalities after ICU treatment in $76 \%$ of unplanned geriatric trauma patients and $46 \%$ in planned orthopedic patients [18]. This fits our results of unplanned geriatric trauma patients in the pICU cohort, showing a 1-year mortality rate of $59 \%$.
Most studies do not differentiate between short- and long-term ICU treatment, very likely because the admission diagnoses of most collectives are composed inhomogeneously, displaying the ICU stay itself as a joint feature. Like mentioned above, we subdivided the ICU collective into sICU and pICU cohorts. This decision was made because we saw a great difference in the underlying ICU treatment indications in these 2 groups. Patients in the sICU cohort were often admitted for a short period of postoperative inotropic support or with postoperative bleeding with a need for transfusion due to the intake of blood-thinning medications. Admission diagnoses in the pICU group often required more extensive care, as shown in Table 4.

Plenty of confounders influence the outcome of geriatric hip-fracture patients. Reducing the time between admission and operative treatment is seen as one important factor for improving survival. There are many articles that have assessed this, and a consensus has been agreed upon that a delay of more than 48 hours is unfavorable to survival $[19,20]$. Some new studies focusing on 30-day mortality after adjusting for well-known risk factors, such as age, comorbidities, and gender, could show an elevated mortality following more than 12 hours of delay to surgery [21] or even an elevated 90-day mortality following a delay of more than $24 \mathrm{~h}$ [22]. As mentioned in Section 3, all patients underwent operative treatment for hip-related fracture in between the first 12$24 \mathrm{~h}$. The pICU cohort was operated on with a slight but significant delay compared to the sICU cohort $(17.2 \pm 0.8 \mathrm{~h}$ versus $23.3 \pm 2.3 \mathrm{~h}, p=0.041$ ). Thus, this significance may influence mortality rates in between our groups, even though this difference of a few hours doubtfully can be considered to display clinical relevance.

As expected, CCI was significantly higher in the pICU cohort, and higher CCI presented as an independent risk factor for higher 6- and 12-month mortality in performed multivariate analysis (Table 3 ). This higher level of comorbidities is well known to be associated with poorer outcomes in hipfracture patients [23]. As obese and old patients are known to be more likely to develop adverse outcomes following a primary total-hip replacement, BMI was taken into account as well. Patients of all groups showed rather normal weight or underweight, displaying no statistical significance. The variables age, ASA score, BI, and gender in nICU, sICU, and pICU cohorts showed no statistically significant differences as well.

Apart from all these known confounders for adverse outcomes, we assume that 1 further, huge factor of influence for prolonged ICU treatment was displayed by the demand of ICU-dependent procedures like invasive ventilation or hemodiafiltration.

Particularly, pulmonary complications and renal failure due to a preexisting chronic failure appeared to be severe and life-threatening complications in geriatric trauma patients. Some prospective studies focusing on the influence of age on the outcome of mechanically ventilated elderly patients showed that age has an important effect on the outcome of mechanically ventilated patients $[24,25]$. In our collective, in-hospital mortality occurred in $68 \%$ of patients 
with mechanical-ventilation-dependent respiratory complications. This impressively illustrates the fatal consequence of this "third hit," following trauma as a "first hit" and operative treatment as a "second hit." Ninety-two percent of these patients died within the first year after admission, and all survivors showed a need for nursing care after 12 months.

Concerning renal failure, recent epidemiological studies have reported an association between reduced glomerular filtration rate and increased risk of death and cardiovascular events [26], as well as the association between renal impairment, frailty, and quality of life. Elderly people with chronic renal insufficiency are known to have a high prevalence of frailty, which may signal their risk for progression to adverse health outcomes [27]. Irrespective of this known data, the finding that only 1 out of 11 patients undergoing hemodiafiltration during ICU stay in our collective survived the first year underlines the severe prognostic character of this procedure.

After all, keeping in mind that only $8 \%$ of patients with invasive ventilatory management and $9 \%$ of patients undergoing CVVHDF survived the first year-and none of them survived without nursing-care need-prognosis in cases of such complications worsens remarkably. Over the years, plenty of studies have confirmed that the majority of patients do not wish to survive if they lose their independence, if they become a burden on their families, or if they are unable to retain their capacity to think clearly [28, 29]. A current empirical analysis showed that if treatment is invasive and the predicted outcome is survival with severe functional impairment or cognitive impairment, $74.4 \%$ and $88.8 \%$ of patients surveyed, respectively, would not choose treatment [30]. There is a bright recognition that the burden of the proposed treatment and the probability of adverse outcomes should be specifically discussed with relatives or legal representatives when talking about end-of-life decisions in the course of intensive-care therapy [31]. Particularly, longterm results after invasive ventilation or hemodiafiltration during acute-care treatment were disastrous in our cohort. These data have to be taken into account, since short-term survival is probably not the most important factor considered when making treatment decisions in this vulnerable cohort of geriatric trauma patients. Clinicians, as well as relatives, should be aware that a patient's appraisal about what constitutes an acceptable long-term outcome may change with advancing age.

The present study has some limitations: Cohorts requiring CVVHDF and IVM were small and preexisting medical conditions and admission diagnoses were manifold. Further, because of different healthcare conceptions in different European countries (and even between different provinces in Germany), a comparison of duration of ICU stay and hospitalization period with other studies is not reasonable overall. Finally, due to the high mortality rate after 1 year, the claimed 1-year nursing-care status is certainly emphasizing a worse outcome but is not satisfactorily valid.

However, for ICU treatment extending past the normal postoperative observational period of 1 to 3 days, we found considerable differences in mortality and nursing-care need after 6 months and 1 year. Particularly, patients requiring CVVHDF or IVM had disastrous long-term results.

Data dealing with outcome parameters concerning patients obtaining CVVHDF- and IVM-dependent complications remain sparse, but the current investigation adds information that might be helpful in decision making serving this vulnerable patient cohort.

\section{Disclosure}

Daphne Eschbach is responsible on behalf of the authors.

\section{Conflict of Interests}

The authors declare that there were no further financial and personal relationships with other people or organizations that could inappropriately influence (bias) their work like employment, consultancies, stock ownership, honoraria, paid expert testimony, patent applications/registrations, or grants or other funding (like National Institutes of Health (NIH), Welcome Trust, or the Howard Hughes Medical Institute (HHMI)).

\section{Authors' Contribution}

All authors declare that they participated in the collection of data, analysis, interpretation, and writing of the paper and that they have approved the final version.

\section{Acknowledgment}

The authors thank their study nurse, A. Dersch, for being a great logistical support.

\section{References}

[1] K. Kinsella and V. A. Velkoff, An Aging World, Series P95/01-1, US Census Bureau, Washington, DC, USA, 2001.

[2] United Nations, Department of Economic and Social Affairs, and Population Division, "World population ageing 2013," Tech. Rep. ST/ESA/SER.A/348, United Nations, Department of Economic and Social Affairs, Population Division, 2013.

[3] S. M. White and R. Griffiths, "Projected incidence of proximal femoral fracture in England: a report from the NHS Hip Fracture Anaesthesia Network (HIPFAN)," Injury, vol. 42, no. 11, pp. 1230-1233, 2011.

[4] M. R. Law, N. J. Wald, and T. W. Meade, "Strategies for prevention of osteoporosis and hip fracture," British Medical Journal, vol. 303, no. 6800, pp. 453-459, 1991.

[5] S. L. Greenspan, E. R. Myers, L. A. Maitland, N. M. Resnick, and W. C. Hayes, "Fall severity and bone mineral density as risk factors for hip fracture in ambulatory elderly," The Journal of the American Medical Association, vol. 271, no. 2, pp. 128-133, 1994.

[6] Network GR, "Acute Care Hip Fracture Clinical Pathway," October 2011, http://www.gtarehabnetwork.ca/clinical-care-guidelines-hip-fracture.

[7] SIGN, Management of Hip Fracture in Older People-A National Clinical Guideline, Scottish Intercollegiate Guidelines Network, Edinburgh, UK, 2009. 
[8] C. L. Sprung, D. Geber, L. A. Eidelman et al., "Evaluation of triage decisions for intensive care admission," Critical Care Medicine, vol. 27, no. 6, pp. 1073-1079, 1999.

[9] E. Simchen, C. L. Sprung, N. Galai et al., "Survival of critically ill patients hospitalized in and out of intensive care units under paucity of intensive care unit beds," Critical Care Medicine, vol. 32, no. 8, pp. 1654-1661, 2004.

[10] G. Joynt, C. Gomersall, P. Tan, A. Lee, C. Cheng, and E. Wong, "Prospective evaluation of patients refused admission to an intensive care unit: triage, futility and outcome," Intensive Care Medicine, vol. 27, no. 9, pp. 1459-1465, 2001.

[11] G. Djaiani and S. Ridley, "Outcome of intensive care in the elderly," Anaesthesia, vol. 52, no. 12, pp. 1130-1136, 1997.

[12] G. E. Rosenthal, P. J. Kaboli, M. J. Barnett, and C. A. Sirio, "Age and the risk of in-hospital death: insights from a multihospital study of intensive care patients," Journal of the American Geriatrics Society, vol. 50, no. 7, pp. 1205-1212, 2002.

[13] D.-A. Eschbach, L. Oberkircher, C. Bliemel, J. Mohr, S. Ruchholtz, and B. Buecking, "Increased age is not associated with higher incidence of complications, longer stay in acute care hospital and in hospital mortality in geriatric hip fracture patients," Maturitas, vol. 74, no. 2, pp. 185-189, 2013.

[14] R. Marks, "Hip fracture epidemiological trends, outcomes, and risk factors, 1970-2009," International Journal of General Medicine, vol. 3, pp. 1-17, 2010.

[15] F. Hu, C. Jiang, J. Shen, P. Tang, and Y. Wang, "Preoperative predictors for mortality following hip fracture surgery: a systematic review and meta-analysis," Injury, vol. 43, no. 6, pp. 676-685, 2012.

[16] S. Ewig, N. Birkner, R. Strauss et al., "New perspectives on community-acquired pneumonia in 388406 patients: results from a nationwide mandatory performance measurement programme in healthcare quality," Thorax, vol. 64, no. 12, pp. 10621069, 2009.

[17] A. Mukhopadhyay, B. C. Tai, K. C. See et al., "Risk factors for hospital and long-term mortality of critically ill elderly patients admitted to an intensive care unit," BioMed Research International, vol. 2014, Article ID 960575, 10 pages, 2014.

[18] V. Pavoni, L. Gianesello, L. Paparella, L. T. Buoninsegni, E. Mori, and G. Gori, "Outcome and quality of life of elderly critically ill patients: an Italian prospective observational study," Archives of Gerontology and Geriatrics, vol. 54, no. 2, pp. e193-e198, 2012.

[19] N. Simunovic, P. J. Devereaux, S. Sprague et al., "Effect of early surgery after hip fracture on mortality and complications: systematic review and meta-analysis," Canadian Medical Association Journal, vol. 182, no. 15, pp. 1609-1616, 2010.

[20] T. Shiga, Z. Wajima, and Y. Ohe, "Is operative delay associated with increased mortality of hip fracture patients? Systematic review, meta-analysis, and meta-regression," Canadian Journal of Anesthesia, vol. 55, no. 3, pp. 146-154, 2008.

[21] C. P. Bretherton and M. J. Parker, "Early surgery for patients with a fracture of the hip decreases 30-day mortality," Bone and Joint Journal B, vol. 97, no. 1, pp. 104-108, 2015.

[22] A. M. Nyholm, K. Gromov, H. Palm, M. Brix, T. Kallemose, and A. Troelsen, "Time to surgery is associated with thirtyday and ninety-day mortality after proximal femoral fracture: a retrospective observational study on prospectively collected data from the Danish Fracture Database Collaborators," The Journal of Bone \& Joint Surgery-American Volume, vol. 97, no. 16, pp. 1333-1339, 2015.
[23] S. Sakan, D. B. Pavlovic, M. Milosevic et al., "Implementing the Surgical Apgar Score in patients with trauma hip fracture," Injury, vol. 46, supplement 6, pp. S61-S66, 2015.

[24] M. D. Zilberberg and S. K. Epstein, "Acute lung injury in the medical ICU: comorbid conditions, age, etiology, and hospital outcome," American Journal of Respiratory and Critical Care Medicine, vol. 157, no. 4, part 1, pp. 1159-1164, 1998.

[25] J. P. Nunn, J. S. Milledge, and J. Singaraya, "Survival of patients ventilated in an intensive therapy unit," British Medical Journal, vol. 1, pp. 1525-1527, 1979.

[26] L. G. Glynn, D. Reddan, J. Newell, J. Hinde, B. Buckley, and A. W. Murphy, "Chronic kidney disease and mortality and morbidity among patients with established cardiovascular disease: a West of Ireland community-based cohort study," Nephrology Dialysis Transplantation, vol. 22, no. 9, pp. 25862594, 2007.

[27] M. G. Shlipak, C. Stehman-Breen, L. F. Fried et al., "The presence of frailty in elderly persons with chronic renal insufficiency," American Journal of Kidney Diseases, vol. 43, no. 5, pp. 861-867, 2004.

[28] T. R. Fried, E. H. Bradley, V. R. Towle, and H. Allore, "Understanding the treatment preferences of seriously ill patients," The New England Journal of Medicine, vol. 346, no. 14, pp. 1061-1066, 2002.

[29] G. E. Mead, S. T. O’Keeffe, C. I. Jack, A. M. Maèstri-Banks, J. R. Playfer, and M. Lye, "What factors influence patient preferences regarding cardiopulmonary resuscitation?" Journal of the Royal College of Physicians of London, vol. 29, no. 4, pp. 295-298, 1995.

[30] L. P. Scheunemann, T. V. Cunningham, R. M. Arnold, P. Buddadhumaruk, and D. B. White, "How clinicians discuss critically ill patients' preferences and values with surrogates? an empirical analysis," Critical Care Medicine, vol. 43, pp. 757-764, 2015.

[31] A. Manara, "Bespoke end-of-life decision making in ICU: has the tailor got the right measurements?" Critical Care Medicine, vol. 43, no. 4, pp. 909-910, 2015. 


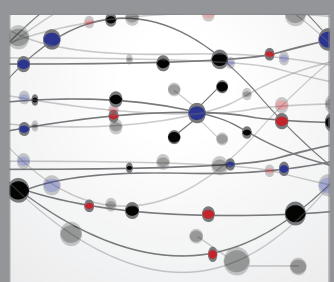

The Scientific World Journal
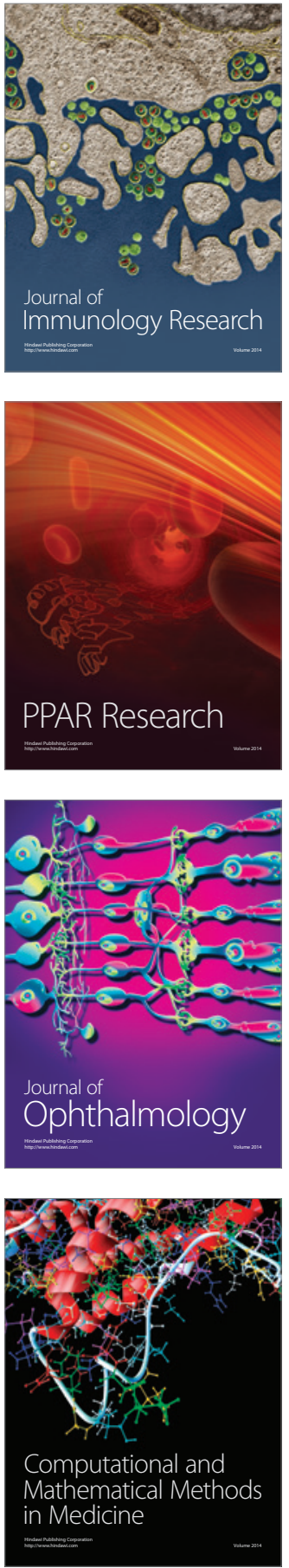

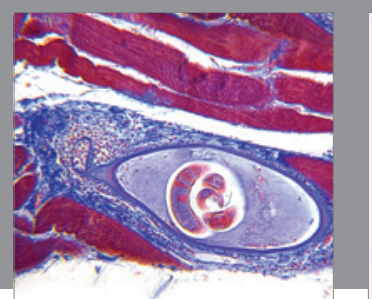

Gastroenterology Research and Practice

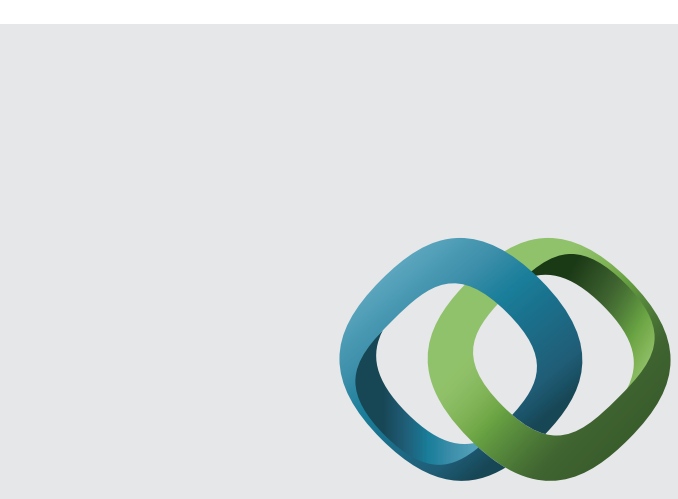

\section{Hindawi}

Submit your manuscripts at

http://www.hindawi.com
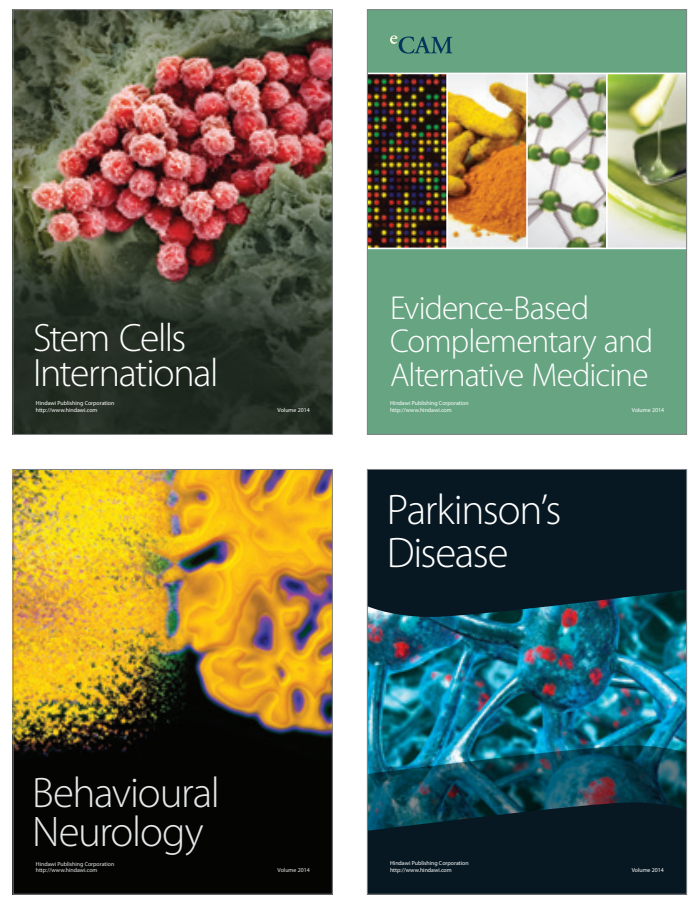
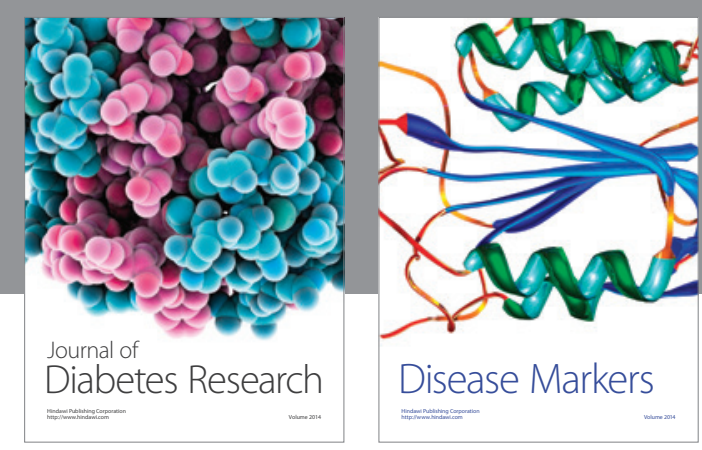

Disease Markers
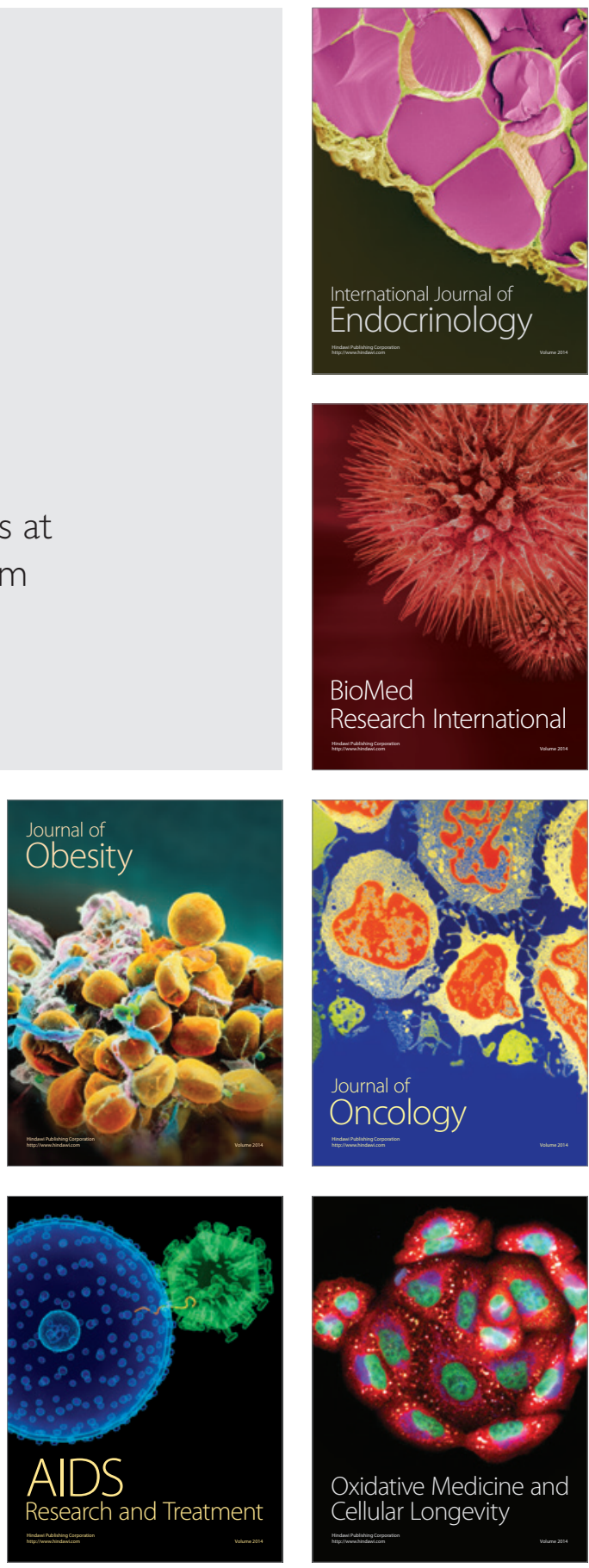